\title{
Como o coletivo Opavivará! pode ajudar Rancière e Bourriaud a fazerem as pazes
}

Pedro Caetano Eboli*

RESUMO: Este artigo se constrói a partir de uma reflexão sobre a crítica rancieriana ao estatuto político se advoga para os trabalhos de Arte Relacional de Nicolas Bourriaud. Rancière parte do pressuposto de que eles sejam permeados por um conjunto de lógicas que ao mesmo tempo os impulsiona na direção daquilo que o filósofo denomina como regime ético das artes e o distancia do regime estético. Tomando os trabalhos do coletivo Opavivará! como exemplares que Bourriaud reuniria sob a chancela da Estética Relacional, procuro elucidar de que forma podemos localizar neles ambos os devires. A fins demonstrativos, procurei partir de uma sensibilidade eminentemente estética para analisar alguns trabalhos do Opavivará!, coletivo de arte assumidamente ligado aos pressupostos da Estética Relacional.

PALAVRAS-CHAVE: política da estética, coletivo Opavivará!, estética relacional ABSTRACT: This article is build upon a reflection on Rancière's criticism on political status of Nicolas Bourriaud's Relational Aesthetics. Rancière assumes that theese art pieces are permeated by a set of logics that at the same time propels them toward what the philosopher calls the ethical regime of the arts, and distance them from the aesthetical regime. Taking the works of the collective Opavivará! as exemplars that Bourriaud would gather under the seal of Relational Aesthetics, I try to elucidate in which ways we could locate them in both logics. For purposes of demonstration, I sought to start from an eminently aesthetic sensibility to analyze some works of the Opavivará!, collective of art admittedly linked to the presuppositions of Relational Aesthetics.

KEYWORDS: politics of aesthetics, Opavivará! ensemble, relational aesthetics

\footnotetext{
*Pedro Caetano Eboli é graduado em Desenho Industrial pela UFRJ, tendo estudado um ano como intercambista no Politecnico di Torino, Itália. É Mestre em Design e Sociedade pela PUC-Rio, onde atualmente cursa o Doutorado. Lá investiga as relações entre corpo, arte e cidade por intermédio da atuação de coletivos urbanos.
} 


\section{Pequena introdução}

Construo este artigo a partir das críticas lançadas pelo filósofo Jacques Rancière (2012) ao estatuto político se advoga para os trabalhos de Arte Relacional, categoria cunhada pelo crítico de arte francês Nicolas Bourriaud (2009). Grosso modo, o filósofo argumenta que eles partem de um conjunto de lógicas que os impulsiona inevitavelmente na direção daquilo que ele denomina como regime ético das artes. Isto, por sua vez, subtrai alguns dos elementos segundo os quais a arte tangencia a política no regime estético. Ora, o próprio filósofo compreende que estes regimes não seguem a uma lógica histórica de ruptura, mas se interpenetram, como extratos assincrônicos de tempo, que podem até mesmo habitar simultaneamente um trabalho de arte. Assim, questiono até que ponto, em plena vigência do regime estético, seja possível atribuir à Arte Relacional um único devir ético que lhe subtraia por completo sua potência política. Afinal, quando nos referimos ao regime estético não tratamos apenas de uma lógica que subjaz à produção dos trabalhos artísticos, mas também aos modos de subjetividade específicos que presidem a sua recepção pelo espectador. A fins demonstrativos, procurarei partir de uma sensibilidade eminentemente estética para analisar alguns trabalhos do Opavivará!, coletivo de arte assumidamente ligado aos pressupostos da Estética Relacional.

\section{Estética Relacional e a crítica rancieriana}

Antes de darmos prosseguimento ao raciocínio convém compreender em que consiste esta categoria cunhada por Bourriaud. Em linhas gerais, o crítico olha retrospectivamente para o aspecto relacional que a arte teria, em forma de latência, invariavelmente assumido ao longo da história, mas que na contemporaneidade passaria a aflorar como matéria constitutiva e primordial de diversos trabalhos artísticos. Desta maneira, a arte do presente iria na contramão de qualquer devir autônomo ou elitista, mas estaria encarregada da produção de laços sociais, seja em espaços expositivos ou fora deles, haja visto que "o contexto social atual restringe as possibilidades de relações humanas" (BOURRIAUD, 2009, p. 23). Mas é justamente na produção destes laços pessoais que a política se manifestaria em sua forma primeira, à revelia dos alienantes processos contemporâneos de individualização dos sujeitos. Partindo deste ponto de vista, o crítico descreve diversos trabalhos dos anos 1990 onde a criação de relações entre os participantes tenha constituído uma tônica. Ele os aproxima de uma linhagem 
histórica que remonta à arte conceitual dos anos 1960 e 1970, interessada em imaginar outros suportes e tensionar os espaços expositivos.

Em suas palestras, o coletivo Opavivará! vincula sua produção artística à produção daquilo que denominam por dispositivos relacionais. Esta expressão foi apropriada diretamente das ideias do crítico de arte francês Nicolas Bourriaud (2009): "uma obra pode funcionar como dispositivo relacional com certo grau de aleatoriedade, máquina de provocar e gerar encontros casuais, individuais ou coletivos" (p. 42). Este teórico se tornou uma espécie de patrono ideológico dos artistas que, desde a década de 1990, vêm produzindo trabalhos participativos. Entretanto, embora goze de popularidade entre os artistas, os preceitos da Estética Relacional cunhados por Bourriaud suscitaram uma série de querelas no âmbito da teoria e crítica da arte (ver PRADO, 2011), especialmente naquilo que tange à filiação política que suas análises advogam para os trabalhos deste tipo.

Jacques Rancière seria um destes detratores, mas para compreender seu ponto de vista precisaremos introduzir alguns de seus conceitos. O filósofo afirma a existência de três diferentes lógicas subjacentes à produção artística, listados na ordem cronológica de seu aparecimento: os regimes ético, representativo e estético. Apesar de estarem relacionados a períodos históricos específicos, estes regimes artísticos podem coexistir e se imbricar, de forma semelhante às epistemês foucaultianas ${ }^{1}$. Rancière compreende que o regime estético da arte, aquele presidido por um conjunto de lógicas de criação e recepção que tomaram corpo especialmente a partir dos modos de subjetividade da Era Democrática, significa uma abertura para as potências do dissenso como união inextricável entre a arte e a política.

Neste período histórico a arte teria passado a operar justamente no momento liminar em que as lógicas da experiência comum são suspensas, em que é aberto espaço para novos recortes sensíveis e possibilidades de múltiplas atribuições de sentidos. Esta suspensão da ordem é justamente a tarefa da política, que questiona uma determinada apreensão dos sentidos naturalizada e tornada real pela máquina policial². A arte no regime estético depende desta redistribuição da partilha do sensível, que a relaciona fatalmente a uma certa forma de política. Mas para desempenhar tal tarefa, a criação artística deve manter uma opacidade interna que resista aos meios unívocos de interpretação. A política do regime estético da arte implica abdicar da tentativa de veicular mensagens, aquilo que Rancière entende como sendo o devir pedagógico da arte politizada, mas deve pressupor um espectador emancipado. 
Para isso, é fundamental que ela envolva certa dosagem entre logos e pathos, uma "identidade de contrários" (RANCIĖRE, 2010), entre o consciente e o inconsciente, pensado e impensado, ação e passividade etc. O sentido é uma construção que se dá entre o espectador e a obra, não do artista ao espectador via obra. Surge aí outro aspecto micropolítico suscitado pelo regime estético da arte: a relação entre espectador e obra envolve a produção ativa de um sujeito, como um processo de singularização que resiste à possibilidade de sujeição e controle sobre os corpos. Desta forma, o dissenso surge como amálgama definitiva entre a política e o regime estético da arte, independentemente dos temas de que o fato artístico possa ser palco. As rupturas com o regime comum do sentir inauguram possibilidades outras de experimentação corpórea, em uma política que emerge da imanência do fato artístico. Desta forma, não é possível compreender a política da estética nos termos de uma eficácia: a arte não pode realizar a promessa da política. A política da arte está exatamente em produzir frestas por onde possa emergir um sujeito: ela está justamente na potência singular que os modos de subjetivação são capazes de engendrar.

No bojo da Estética Relacional, Jacques Rancière certamente traria críticas relativas à filiação política dos trabalhos do coletivo Opavivará!. Isto porque eles partem de uma lógica que os impulsiona inevitavelmente na direção daquilo que o filósofo denominaria como regime ético das artes, tanto no que tange a um esboroamento das fronteiras entre arte e vida, quanto no sentido de abrigar uma preocupação referente ao ethos da comunidade. Mas ao ir nesta direção

Esse paradigma [do regime ético] designa o lugar da política da arte, mas para logo depois subtrair a arte e a política juntas. Substitui a duvidosa pretensão da representação a corrigir os costumes e os pensamentos por um modelo arquiético. Arquiético não no sentido de que os pensamentos já não são objetos de lições dadas por corpos ou imagens representados, mas estão diretamente encarnados em costumes, em modos de ser da comunidade. Esse modelo arquiético não deixou de acompanhar o que chamamos de modernidade, como pensamento de uma arte que se tornou forma de vida (RANCIÈRE, 2012, p. 56).

Talvez seja justamente no paradigma ético que a crítica institucional do coletivo se situa, à reboque dos discursos clamando pela evasão da arte dos espaços das galerias e pelo fim à passividade do espectador, que deve transcender sua posição de mero observador para participar dos trabalhos de corpo inteiro. Ora, o filósofo recusa quaisquer dicotomias que contraponham sumariamente um olhar passivo a um agir ativo, uma vez que "olhar também é uma 
ação que confirma ou transforma essa distribuição das posições. O espectador também age (...). Ele observa, seleciona, compara, interpreta" (RANCIÈRE, 2012, p. 17). Assim, Rancière sinaliza que as condições de possibilidade para a política da arte no regime estético envolvem a assunção de um espectador emancipado e que a "arte crítica é uma arte que sabe que seu efeito político passa pela distância estética" (p. 81).

Os trabalhos do coletivo dependem da vida e da variabilidade da ação humanas, das formações grupais "espontâneas". Esta interação humana é aquilo que dita seu "sucesso" e o coletivo pensa de antemão nesta potência, como uma espécie de télos ou modelo de eficácia. Afinal, em última instância eles compartilham deste desejo de criar elos sociais, quaisquer que sejam. Os gestos de intencionalidade parecem ir nesta direção, bem como um pensamento quanto aos efeitos que os trabalhos devem produzir. A denúncia de Jacques Rancière (2012) dirigida aos trabalhos de arte relacional quanto à falta de "distância estética", lógica fundamental para uma política imanente à arte, vai justamente nesta direção.

\section{Questionando a crítica rancieriana}

Entretanto, é inegável que os trabalhos do coletivo sejam também atravessados por uma forma de sensibilidade específica do regime estético, aquela que pressupõe a "igualdade de todos os temas" (RANCIÈRE, 2009, p. 19), e que entendo habitar o âmago de suas operações apropriativas. Jacques Rancière (2009) deduz desta máxima um fio histórico de continuidade inaugurado pelo Romantismo que atravessa toda a produção artística na Era Democrática, permeando fortemente a Arte Moderna e Contemporânea. Com algumas das vanguardas modernas talvez os trabalhos do coletivo compartilhem do ímpeto inicial de fazer eclodir as distinções que erigem fronteiras estritas entre a alta e a baixa cultura, radicalizando as operações que colocam a arte em relação de contiguidade com a vida. Mas é também sob a égide de uma sensibilidade estritamente estética que ele opera seu olhar antropofágico em um sem número de objetos, situações e personagens urbanos cujas presenças poderiam facilmente passar despercebidas. O Opavivará! os deglute, fazendo emergir uma poesia impura.

Mas ao contrário das operações vanguardistas tais como assemblages ou readymades, das quais o coletivo é certamente tributário, as apropriações aqui não parecem se tratar apenas de deslocamentos provocativos, mudanças de circuito que visibilizam o "vale-tudo" da matéria 
artística contemporânea. Esta questão certamente aparece, mas como ponto de partida ou riso à História da Arte. Aqui se os objetos são retirados de seu contexto, por vezes modificados, eles ainda preservam seu caráter utilitário, e mais: eles só existem em ato e em ato coletivo. Mas ao trazer à luz estes objetos, situações e personagens urbanos, expondo-os como Arte Contemporânea, o coletivo também não procura falar do outro ou dar-lhe voz, mas erigir uma espécie de inventário que precisamente recorta e desloca para o interior de uma poética coerente, embora muitas vezes insólita.

Aqui me empenho na recusa dos ditames autoritários de uma escrita neutra, transcendental, que olha como que de cima para um objeto de pesquisa, e o domina, o esgota discursivamente. Dispenso a autoridade etnográfica que me imporia os imperativos empíricos da experiência imediata de cada um dos trabalhos do coletivo Opavivará! que procurarei abordar, embora compreenda o paradoxo de afirmar a potência sensível do corpo estando atrás de uma asséptica tela de computador. Longe de procurar encerrar as possibilidades de sentido que atravessam o fato artístico, me construo enquanto sujeito e proponho um exercício de abstração que me transporta no espaço e no tempo e me coloca frente àquilo que estou interpretando. Pensemos então os trabalhos como ponto de partida para a formulação performativa de uma prática de escrita, que procura incorporar o prazer do texto como simulação da existência de um corpo que escreve. Afinal, como falar dos processos de subjetivação política que a estética é capaz de engendrar me situando do lado de fora de um corpo? Por mais que eu olhe para algo que me é externo, nada sai que não me faça parte: não consigo falar do outro.

Portanto, não busco analisar os trabalhos do coletivo Opavivará! de acordo com aquilo que são, mas enunciar de que forma eles me mobilizam e acontecem em mim. Acredito que a sensibilidade do regime estético me autorize a tarefa sempre incompleta, parcial e contingente de cartografar estes afetos, embora permaneçam sempre alguns excessos que resistem à redução intelectiva do fato artístico. Nesta busca racional de conter estes transbordamentos, sou constantemente acometido por um exaurimento inevitável do meu próprio corpo, espremido para que dele saia texto. A própria escrita parece me deslocar, como coloca Michel Foucault (1984):

O "ensaio" - que é necessário entender como experiência modificadora de si no jogo da verdade, e não como apropriação simplificadora de outrem para fins de comunicação - é o corpo 
vivo da filosofia, se pelo menos, ela ainda for hoje o que era outrora, ou seja, uma "ascese", um exercício de si, no pensamento (p. 13).

Mas o esforço para delinear a forma como os trabalhos do coletivo acontecem em mim não busca me colocar como a voz única e autoritária, impermeável aos atravessamentos de outras obras e discursos. Esta produção de sentidos é inevitavelmente colonizada por outras vozes que ouvi e mal posso localizar, e habitada por impressões incertas que se acumulavam à medida que olhava novamente para os trabalhos. Neste sentido, acredito que seja importante observar as proposições dos coletivos naquilo que transborda à experiência imediata que elas possam proporcionar. Compreendo que a obra de arte no regime estético é munida de uma espécie de força gravitacional que atrai para si tudo aquilo que lhe constela, incluindo as negociações e demais processos que lhe permeiam, como partículas produtoras de sentido. Até mesmo naquilo que diz respeito à relação que os trabalhos do coletivo estabelecem entre si. Portanto, proponho a tarefa híbrida de observá-los individualmente, mas também formando pequenos corpus, dos quais eu possa deduzir algum conjunto de questões, que aos poucos vão compondo uma espécie de coerência poética.

\section{Coletivo Opavivará!}

Trata-se de pequenos delitos táticos, situações incongruentes e comunitárias que produzem rupturas nos fluxos normais da cidade. Mas não há a seriedade cerebral que vemos em muitos trabalhos de Arte Contemporânea, aqui o riso e a relação com o outro tomam corpo. São nossos próprios corpos que escrevem e são postos para vibrar junto com outros corpos: somos incitados a performar. O coletivo Opavivará! produz recortes do mundo que sublinham as dimensões rituais da vida cotidiana, visibilizam o caráter nômade de certos profissionais da rua, ressaltam a dimensão coletiva e ritualística dos objetos e festividades, ou produzem novos fluxos e espaços. Mas trata-se de uma lâmina muito precisa, que primeiro eviscera para depois deslocar, trazendo à luz algo que a inércia das repetições havia cristalizado e invisibilizado. Sua poética me dá acesso a espaços cegos do meu próprio tecido sensível, me expõe à preguiça do aparelho perceptivo, colocado em suspensão momentânea para modificar o tráfego de sentidos e sensações que aqui procuro intelectivamente assentar. Tudo à revelia dos excessos, que insistem em me deslocar de mim mesmo. 
Talvez o apreço especial pelos nômades profissionais das cidades advenha destes deslocamentos liminares do pensamento que os trabalhos do coletivo possibilitam engendrar. Em Eu amo camelô (2009) os indivíduos nômades são vendedores de mate de praia, que estavam sendo proibidos de exercer sua profissão, devido ao Choque de Ordem instalado pelo então prefeito do Rio de Janeiro, Eduardo Paes. Nesta época o coletivo tirou fotos individuais destes vendedores e as transformou em cartões postais com os dizeres "Eu amo camelô," sendo o dinheiro de sua venda repassado aos próprios modelos. Nesta operação o Opavivará! parece entrar na disputa sobre o imaginário simbólico da cidade, embaralhando o regime policiaß ${ }^{\beta}$ que ordena aqueles que merecem ter visibilidade e os que estão destinados à sombra. Sinto como se o coletivo deslocasse ligeiramente a moldura que recorta a praia como paisagem que merece ser vista para a dos camelôs que nela circulam. Em cada cartão a expressão singular de cada um deles. Mas se os vendedores de mate são seres nômades, também é nômade o próprio suporte que contém suas imagens, cuja circulação foge totalmente da possibilidade de controle. Aqui talvez possamos notar uma referência sutil à Arte Postal dos anos 1960.

Em Transnômades (2016) são os carrinhos à tração humana, tão comuns nas cidades, aqui "equipados" para desempenharem um sem número de funções agregadoras ou contemplativas, tais como a preparação de um churrasco, a reunião em torno de um karaokê, locais de descanso etc. Ao longo da $32^{a}$ Bienal de São Paulo estes carrinhos eram ativados periodicamente pelo coletivo, juntamente ao público e carregadores profissionais. Eles eram levados coletivamente para fora do Pavilhão da Bienal em uma carreata nômade que parava de tempos em tempos para ativar as funções dos carrinhos.

Mas há um devir político que atravessa o nomadismo, a deriva como forma de vida, que permanentemente escapa dos mecanismos disciplinares que fixam divisões e atribuem aos corpos localização e identidade precisas. É um vagar sobre o espaço liso, sem centro ou local, que coloca em cena uma força incessantemente desterritorializante (DELEUZE \& GUATTARI, 1997). Enquanto a migração fixa um ponto de partida e outro de chegada, o nomadismo é a liminaridade como estado do ser. Mas se por um lado a mobilidade total pode constituir uma forma individualizante, tal como foi constituída na cidade moderna, de outro ela pode emergir sob a forma de uma "máquina de guerra nômade", que "conquista sem ser notada e se move antes do mapa ser retificado" (BEY, 2004, p. 17). O Opavivará! opera justamente na apropriação e refuncionalização destas máquinas de guerra nômades, análoga à figura cinética 


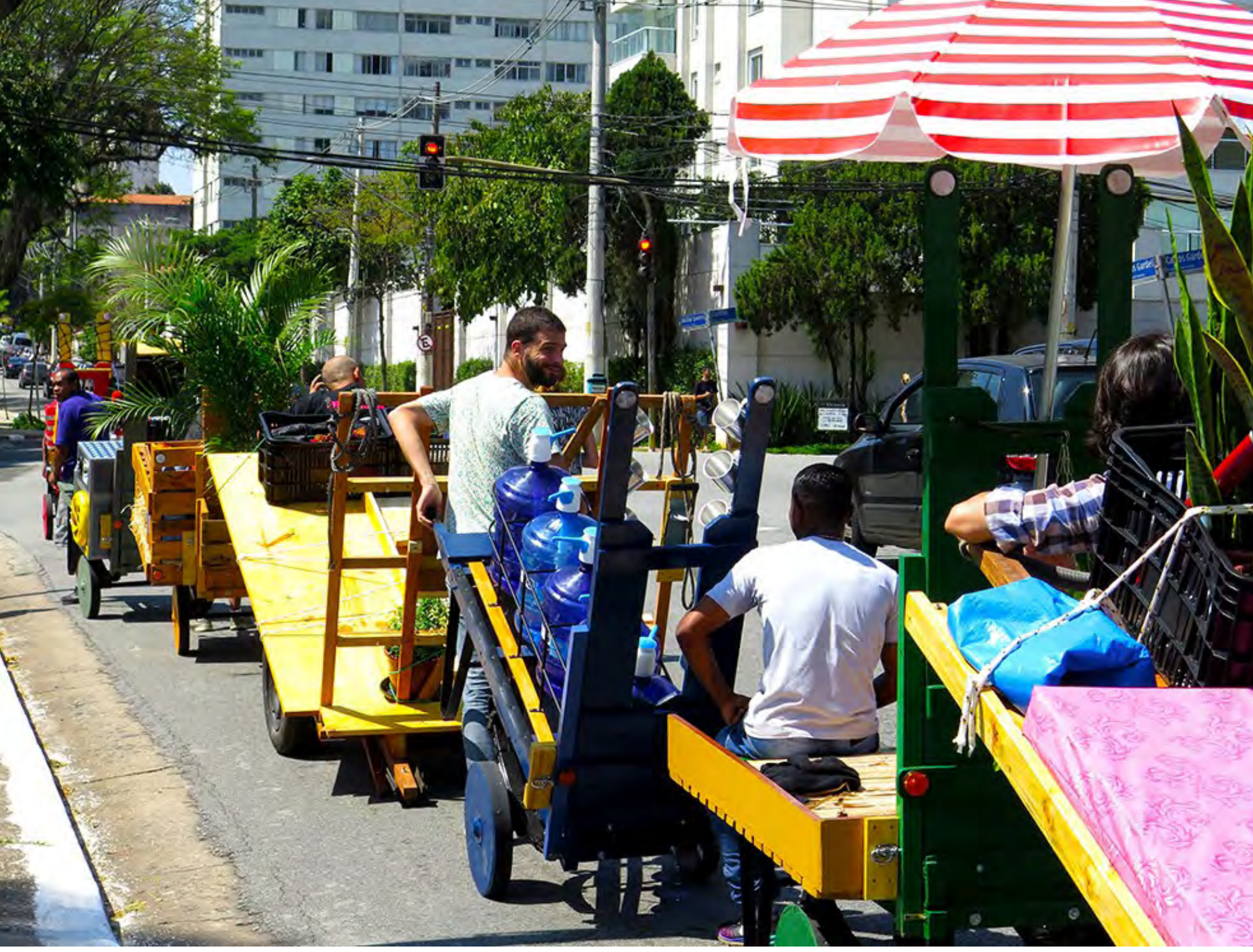


do desviante. Talvez se trate de um nomadismo ideológico e espacial, ciência fluida que se entranha em pequenas frestas e produz uma cartografia de contaminação, como heterotopia ${ }^{4}$ da absoluta movência.

Mas se o nomadismo se constitui como figura temática recorrente na obra do coletivo, também podemos dizer o mesmo de seu gesto oposto: o convite a desacelerar e assumir ativamente uma relação contemplativa com relação à cidade. Este é o caso de $A$ rua é um espetáculo (2011), em que o Opavivará! se mune de suas emblemáticas cadeiras de praia coletivas para criar uma espécie de sala de estar em pleno Centro do Rio de Janeiro, de onde seus membros apenas contemplam a paisagem. A completa estática do grupo atrai curiosos, coagula e aglomera naquele acontecimento alguns dos rápidos corpos que atravessam a calçada. "O que há para ver?", perguntam alguns. Apesar de, à primeira vista, parecer uma ação banal e ingênua, o coletivo está novamente lidando com os regimes de visibilidade, com aquilo que o descuido individualizante do movimento acelerado torna invisível. Se é a polícia que impõe aos corpos os imperativos da frenética circulação, então desacelerar pode também deslindar zonas que o sensível havia deixado cegas:

As intervenções policiais em espaços públicos consistem primeiramente não em interpelar os manifestantes, mas em dispersar a manifestação. A polícia não é a lei que interpela indivíduos (como em Althusser, e o seu "Ei, você aí") (...), seu slogan é: “Circulando, não há nada para ver aqui!". A polícia é aquela que diz que, aqui, nesta rua, não há nada a ser visto e, portanto, nada mais a fazer do que continuar se movendo. Ela afirma que o espaço para circulação não é mais do que o espaço de circulação. A política, por sua vez, consiste em transformar este espaço de "circulação", de passagem, em um espaço para a aparição de um sujeito (RANCIÈRE, 2010, p. 37, tradução nossa).

Aqui parece emergir a figura da multidão, ao invés daquela da massa, em que o agrupamento ainda deixa espaço para a produção ativa de um sujeito, ou de uma espécie de flâneur, cuja observação cuidadosa dá a ver aquilo que não tinha lugar num campo dado de visibilidade. Em Formosa Decelerator (2015) e Self Service Pajé (2015), a presença de uma lenta cerimônia do chá e redes de balanço também anunciam a desaceleração como plataforma relacional e política. Se para Barthes (2013), a inserção do sujeito no código social está ligada à adequação a um certo ritmo, então pode haver algo de subversivo na lentidão, ou em suas palavras: "no mundo atual, toda técnica de diminuir a velocidade tem algo de progressista" (p. 35). 
A poética do coletivo é recorrentemente habitada por estes dispositivos, ou gatilhos, instalados em diversos espaços da cidade com o objetivo de gerar fissuras na vivência comum dos passantes. A partir deles o Opavivará! produz acontecimentos cujos sentidos nos tragam do lugar comum em direção a experiências não automáticas do corpo na cidade. Em Chuvaverão (2014), por exemplo, o coletivo instalou na parede externa da galeria Gentil Carioca cinco chuveiros públicos, em uma nova operação que eviscera e desloca o interior para a luz. O aspecto cenográfico, recorrente nos trabalhos do Opavivará!, aparece aí de forma peremptória e bem humorada, com a inclusão dos azulejos, de um deck, e locais para os sabonetes, de modo a fazer crer que eles literalmente retiraram um banheiro de seu âmbito privado e o levaram para o espaço público. Este trabalho faz lembrar os imperativos modernos do higienismo nas cidades, ligado diretamente ao branco incorporal das galerias e museus de arte: certa ideia de pureza neutra, que permeia tanto o espaço expositivo quanto alguns ideais de cidade.

Mas Chuvaverão também permite pensar um aspecto micropolítico trabalhado ostensivamente pelo coletivo: a oposição entre os âmbitos do público e do privado, problemática que atravessa de forma semelhante os corpos e a materialidade dos espaços urbanos. Para Jacques Rancière (2010), determinar que categorias tais como mulheres e trabalhadores pertenciam ao espaço "doméstico" e não à "vida pública dos iguais" era uma forma de negar aos seus discursos uma aisthesis partilhada e, portanto, qualquer voz política. Mas se é a polícia que distribui os espaços e corpos de acordo com uma partilha do sensível, então "o aspecto político destas categorias sempre consiste em requalificar estes espaços, em fazê-los serem vistos como lugares de uma comunidade" (RANCIĖRE, 2010, p. 38, tradução nossa). Enquanto a intimidade da nudez e do prazer carnal são destinados ao âmbito privado do lar e da família, em público os corpos dos sujeitos são moralizados pelo olho do poder.

A lógica que rege a produção dos espaços públicos e privados se dá a partir de uma estratégia sem sujeito ${ }^{5}$, permeada pelo pressuposto disciplinar ${ }^{6}$, que se materializa sob a forma de estritas divisões e zoneamentos. Estes espaços físicos, por sua vez, encarnam nos corpos, sob os vultos de um controle disciplinante. Mas a maneira como o poder atua na materialidade das cidades é análoga àquela que se entranha no espaço privado do lar. Foucault (1989) nos elucida

a respeito do fato da casa, até o século XVIII, continuar sendo um espaço indiferenciado. Existem peças: nelas se dorme se come, se recebe, pouco importa. Depois, pouco a pouco, o espaço se especifica e torna-se funcional (...). A família operária será fixada; será prescrito para ela um tipo 


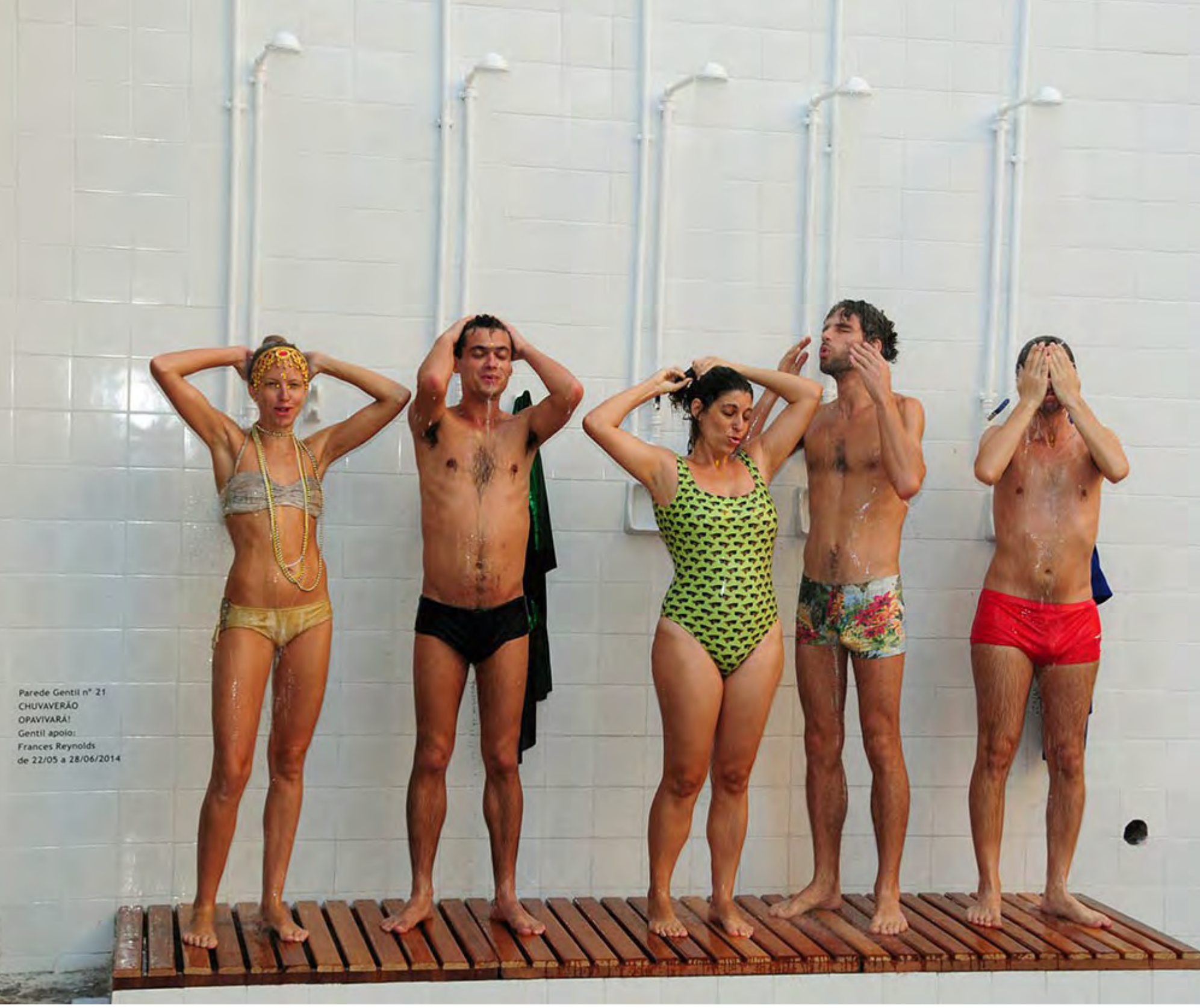

Chuvaverão, Rio de Janeiro, 2014. 
de moralidade, através da determinação de seu espaço de vida, com uma peça que serve como cozinha e sala de jantar, o quarto dos pais (que é o lugar da procriação) e o quarto das crianças. Às vezes, nos casos mais favoráveis, há o quarto das meninas e o quarto dos meninos (p. 211).

Contudo, é justamente criando esta ficção que expele o local da nudez e da higiene íntima do âmago privado do lar, expondo as vísceras de um espaço doméstico, que Chuvaverão abre os corpos para outra possibilidade liminar de vivência na cidade. Esta mesma operação que expõe no avesso as relações entre o público e o privado parece atravessar diversos outros trabalhos, tais como Cozinha Coletiva (2007). Se o poder que reparte e quadricula os interiores do lar é o mesmo que age nas disposições espaciais das cidades, então vemos revelado um ponto em que o público e o privado se insinuam como um contínuo, dadas as forças que thes configuram. Aqui visibilizamos os poderes que moralizam a experiência corpórea nos espaços urbanos, abrindo potências para um pavonear dos corpos que autoriza a possibilidade de uma (semi) nudez em público. Tudo isto em pleno centro da cidade, onde os imperativos da cinética e os ternos dos executivos costumam dar o tom do horizonte visual. A experiência individual do cuidado de si aqui se apresenta em forma de uma grupalidade que preserva a singularidade dos sujeitos.

Se Chuvaverão consiste da operação de tornar público aquilo que era privado, Namoita (2007, 2011 , 2012) realiza o percurso inverso: torna privados pequenos redutos onde os corpos estão escondidos dos olhares. Ele parte de uma operação que se apropria e desloca as moitas urbanas para o espaço expositivo. Estes locais permeáveis e efêmeros, mas protegidos dos olhares, costumam ser palco de uma série de atos imorais ou ilícitos do corpo, tais como o uso de drogas e sexo, dos quais sobram apenas vestígios para a manhã seguinte. Frutos de uma estratégia sem sujeito, estes locais podem ser encontrados nas mais diversas localidades, e dão a ver a forma como destinamos aos prazeres do corpo um espaço recalcado, refugiado do olho do poder. Não se trata aqui de um poder proibitivo, mas aquele que impele a efetividade do ato a um local muito específico, uma cartografia de forças que acaba produzindo estes espaços efêmeros.

O Opavivará! reproduz estes locais protegidos da visibilidade total, onde se desenvolvem ambientes permissivos e tem lugar uma outra forma de sociabilidade. Ali, naquele espaço heterotópico, a salvo da disciplina imposta aos corpos pelos olhares, é aberta a potência dos acasos e dos encontros furtivos com a alteridade. Somos convidados a entrar nesta aconchegante 


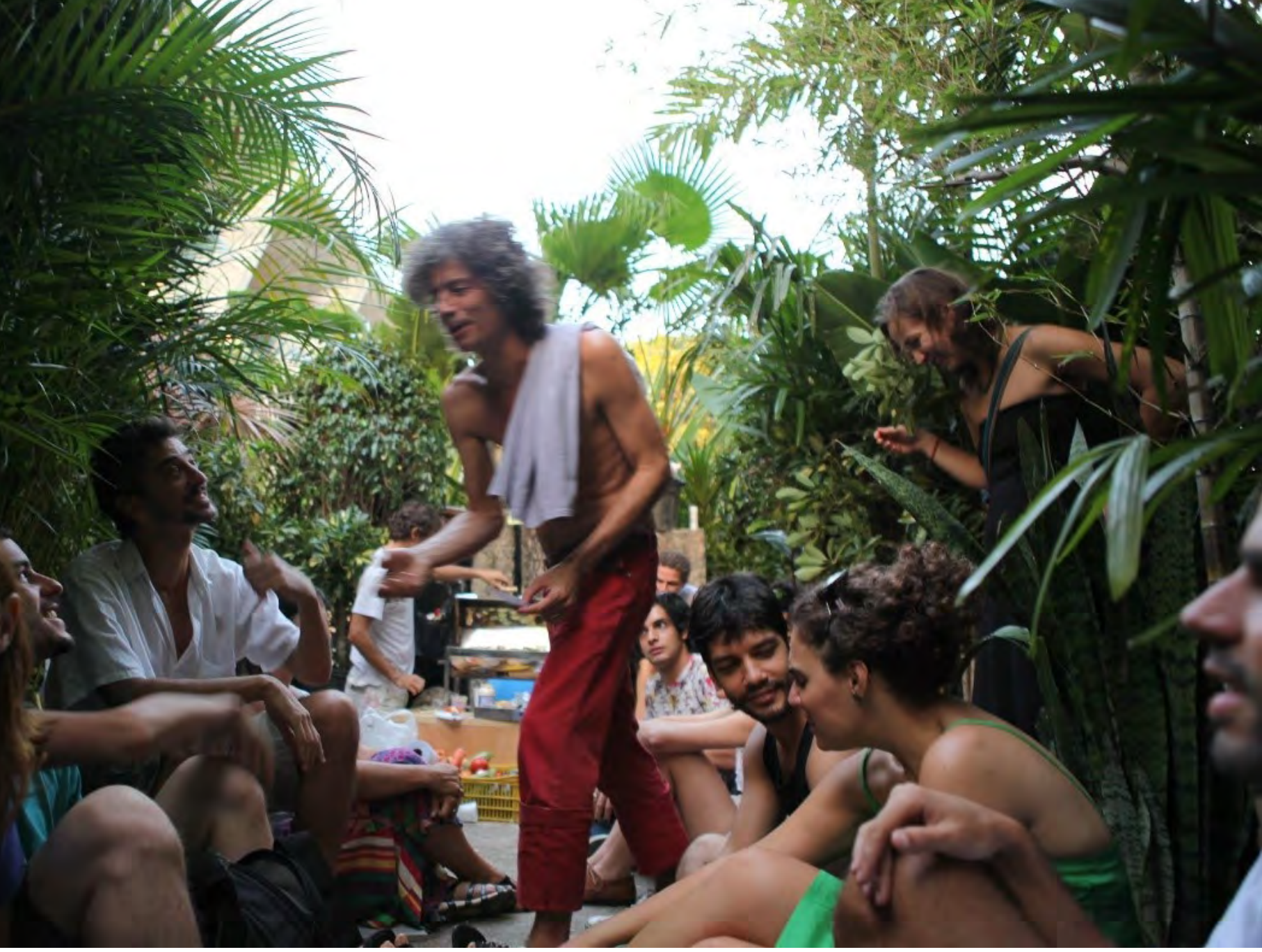


heterotopia de desvio que visibiliza uma das tantas disposições espaciais "espontâneas" que o poder erige. Não por acaso o coletivo relate alguns casos de sexo no espaço deste trabalho. Aqui novamente a questão dos regimes de visibilidade entra em cena: o deslocamento que está na base do trabalho nos permite refletir sobre nossa própria relação com os prazeres do corpo, trazendo à luz algo que parecia escondido nos recônditos da carne e se vê refletido na própria organização espacial da cidade. Como resposta à dimensão retiniana que a arte geralmente assume, os efeitos colaterais de uma moralização pelo olhar. Mas é curioso como este trabalho se mimetiza totalmente na paisagem, a ponto de tornar-se invisível: um interior que é totalmente exótico ao exterior.

\section{Algumas considerações finais}

Aqui, sem compreender totalmente se este exercício serve como uma prova de que há um devir político que atravessa a produção artística do coletivo Opavivará!, ao menos coloquei em movimento os ímpetos foucaultianos de uma escrita ensaística que procura me descolar daquilo que me fixa a mim mesmo. Algo nos termos daquilo que o Foucault compreenderia como processos de subjetivação (FOUCAULT, 1984), de forma semelhante a Jacques Rancière, que compreende a política como "assunto de sujeitos, ou melhor, modos de subjetivação" (RANCIÈRE, 1996b, p. 47). Vemos que embora a poética do coletivo Opavivará! esteja fatalmente imbricada àquilo que Jacques Rancière (2012) chamaria de regime ético, não consigo ignorar que os trabalhos sejam atravessados pela sensibilidade específica do regime estético.

Ou que eu mesmo, enquanto sujeito histórico permeado pelos modos de subjetividade específicos da Era Democrática, seja atravessado pelos devires políticos que estão definitivamente imbricados ao regime estético. Neste sentido, permanece sua potência dissensual, bússola para o exercício de escrita que empreendi. Suas frestas arejadas tornaram possível a minha produção enquanto sujeito, criando pequenos grupos de trabalhos dos quais pude extrair conjuntos de questões concernentes principalmente às relações entre os regimes de visibilidade, algo das analíticas do espaço foucaultianas, o corpo, a cidade e a micropolítica. 


\section{Notas}

1. Deleuze (2005) afirma, a respeito na noção de epistemê: "uma 'época' não preexiste aos enunciados que a exprimem, nem às visibilidades que a preenchem. São os dois aspectos essenciais: por um lado, cada estrato, cada formação histórica implica uma repartição do visível e do enunciável que se faz sobre si mesma; por outro lado, de um estrato a outro varia a repartição, porque a própria visibilidade varia em modo e os próprios enunciados mudam de regime" (p. 58)

2. Emprego o termo polícia segundo a acepção rancieriana. O autor compreende que a organização da partilha do sensível é realizada pela figura que ele denomina por polícia, uma espécie de dispositivo cultural que gere os corpos e vidas em sociedade, de modo a garantir a continuidade e repetição das condições que estão dadas na organização da pólis (RANClÈRE, 1996b).

3. Ver Nota 2

4. Ver "As Heterotopias", in: FOUCAULT, 2013.

5. Michel Foucault (1988), nos elucida sobre as estratégias sem sujeito: “lá, a lógica é perfeitamente clara, as miras decifráveis e, contudo, acontece não haver mais ninguém para tê-las concebido e poucos para formulá-las: caráter implícito das grandes estratégias anônimas, quase mudas, que coordenam táticas loquazes, cujos inventores ou responsáveis quase nunca são hipócritas" (p. 91).

6. Para Michel Foucault (1989) o poder disciplinar surge por volta do século XVII. Endereçado individualmente aos corpos, visando a torná-los dóceis e produtivos, este poder se manifesta nas organizações espaciais de hospitais, escolas, oficinas e prisões. Ele impõe moralidades sem a força de uma repressão recorrente, mas através da economia de um olhar automático e incessante.

\section{Referências}

BARTHES, Roland. Como viver junto: simulações romanescas de alguns espaços cotidianos. São Paulo: Martins Fontes, 2013.

BEY, Hakim. Taz: Zona Autônoma Temporária. São Paulo: Conrad, 2004.

BOURRIAUD, Nicolas. Estética Relacional. São Paulo: Martins Fontes, 2009.

DELEUZE, Gilles. Foucault. São Paulo: Brasiliense, 2005.

\& GUATTARI, Felix. Mil platôs - capitalismo e esquizofrenia, volume 5. São Paulo: Ed. 34, 1997

FOUCAULT, Michel. História da Sexualidade II: o uso dos prazeres. Rio de Janeiro: Graal, 1984.

História Da Sexualidade I: A Vontade De Saber. Rio de Janeiro: Graal, 1988.

Microfísica do Poder. Rio de Janeiro: Graal, 1989.

Vigiar e punir. nascimento da prisão. Petrópolis: Vozes, 2009.

A ordem do discurso: aula inaugural no Collège de France, pronunciada em 2 de dezembro de 1970. São Paulo:

Loyola, 2012

O Corpo Utópico, As Heterotopias. São Paulo: n-1 edições, 2013. 
PRADO, Marcela. Debate crítico alrededor de la Estética Relacional. In: Revista Disturbis, v. 10. Barcelona: Universitat Autònoma de Barcelona, 2011

RANCIÈRE, Jacques. O dissenso. In: A crise da razão. Adauto Novaes (Org.). São Paulo: Companhia das Letras, 1996a. O Desentendimento: política e filosofia. São Paulo: Ed. 34, 1996b. A partilha do sensível. São Paulo: Editora 34, 2009.

Dissensus: on politics and aesthetics. Londres: Continuum, 2010.

O espectador emancipado. São Paulo: Martins Fontes, 2012. 